\title{
Monitoring and use of antimycotic (micafungin) for systemic use provided by the pharmacy of Marsala Hospital, Italy
}

\author{
Fabio Venturella, Maria Cristina Tumbarello, Laura Navarra, Simona Martorana \\ Department of Scientific, Biological, Chemical and Pharmaceutical Technologies, University of \\ Palermo, Palermo, Italy
}

\begin{abstract}
Micafungin is an antimycotic drug and represents an important addition to the available therapies for the treatment of systemic fungal infections. Micafungin is used: in the treatment of invasive candidiasis, oesophageal and prophylaxis of Candida infections. It inhibits, in a non-competitive way, the synthesis of 1,3- $\beta$-D-glucan, a component of fungal cell wall and is rapidly distributed into the tissues. It has a high-rate respectful bond with plasma protein, which is independent from the concentration of the drug. It is metabolized through the liver, being not subject to intense metabolic transformations until the excretion. There is no evidence of systemic accumulation after repeated use. The steady-state is reached in 4-5 days. Medical records examined at the pharmacy of Marsala Hospital highlight that, from $01 / 06 / 2014$ to $01 / 08 / 2014$, in this hospital 12 vials were used by the hospitalized patients in the Department of Intensive Care: 8 patients between 75 and 83 years old had a body weight (BW) higher than $40 \mathrm{~kg} ; 3$ patients between 40 and 60 years of age had a BW higher than $40 \mathrm{~kg}$, and one 17 year-old patient had a BW of $40 \mathrm{~kg}$. Two patients needed a dose increase, while for the other 10 patients the first dose resulted sufficient. Mycamine ${ }^{\circledR}$ was used for the treatment of hypovolemic post-operative shock. The most recorded adverse reactions were anemia, hypokalemia, hypomagnesemia, phlebitis, nausea, liver problems. Given the different weight of the subjects, the dosage was different.
\end{abstract}

Correspondence: Fabio Venturella, Department of Scientific, Biological, Chemical and Pharmaceutical Technologies, University of Palermo, viale delle Scienze 16, 90128 Palermo, Italy.

Tel: +39.091 .23891265 .

E-mail: fabio.venturella@unipa.it

Key words: Antimycotic; Pharmacy; Sicily.

Received for publication: 19 February 2015.

Revision received: 5 November 2015.

Accepted for publication: 16 December 2015.

CC Copyright F. Venturella et al., 2016

Licensee PAGEPress, Italy

Journal of Biological Research 2016; 89:5113

doi:10.4081/jbr.2016.5113

This article is distributed under the terms of the Creative Commons Attribution Noncommercial License (by-nc 4.0) which permits any noncommercial use, distribution, and reproduction in any medium, provided the original author(s) and source are credited.

\section{Introduction}

The active principle of Mycamine ${ }^{\circledR}$, the micafungin, is a semisynthetic drug mycotic belonging to the group of echinocandins (a new class of antifungal drugs that inhibit glycan synthase enzyme by whom the products are essential for building the fungin wall) and represents an important improvement to current available therapies focused on the treatment of systemic fungal infections, due to its favorable efficacy and tolerability. It belongs to the class of medicines added to the list of drugs subject to intensive monitoring. ${ }^{1-3}$ It is used in the treatment of invasive candidiasis (adults and children, including infants), where the term invasive means that the fungus has spread into the tissues and blood vessels. It is also used in the treatment of esophageal candidiasis in patients (over 16 years) suitable for intravenous therapy and for prophylaxis of Candida infections in patients (adults and adolescents over 16 years of age) undergoing allogeneic hematopoietic stem cell. It is also used in patients who are expected to have neutropenia for 10 or more days. ${ }^{2}$ Obtained by chemical modification of a celomicete fungus fermentation product, the Coleophoma empetri F-11899, micafungin inhibits non-competitively the synthesis of 1,3- $\beta$-D-glucan, an essential component of the fungal cell wall, not present in mammalian cells. ${ }^{4}$ Micafungin exhibits linear pharmacokinetics in adult and pediatric patients. It is rapidly distributed in tissues after intravenous infusion and reaches a volume of distribution at steady state of approximately 18-19 Lh. It binds plasma proteins, mainly serum albumin, at high rate (>99\%). This binding is independent from drug concentration in a range between 10 and $100 \mathrm{~g} / \mathrm{mL}$. Micafungin is metabolized in the liver but it does not assume a significant involvement of cytochrome P450. Furthermore, it is not subjected to intense metabolic transformations before excretion. Although in vitro studies have shown that micafungin is a substrate of CYP3A, hydroxylation by this enzyme is not a critical step in its metabolism in vivo. The total clearance was between 0.15 and $0.3 \mathrm{~mL} / \mathrm{min} / \mathrm{kg}$ (in healthy subjects and in adult patients) and is independent from dose. There is no evidence of systemic accumulation after repeated administration. Steady-state is generally reached within $4-5$ days. ${ }^{5}$ Drug interaction studies were conducted in healthy subjects to evaluate the potential for interaction among micafungin and mycophenolate mofetil, cycloserine, tacrolimus, prednisolone, sirolimus, nifedipine, fluconazole, ritonavir, rifampicin, itraconazole, voriconazole and amphotericin B. In these studies, altered pharmacokinetics of this echinocandin were not evidenced. Further adjustments of micafungin dose are not required when these drugs are administered concomitantly. Echinocandins represent antifungals with fewer problems of drug interactions. ${ }^{6}$ Conversely, amphotericin B have multiple drug interactions that complicate patient management, due to possible occurrence of side effects, which is especially true for azoles. 


\section{Materials and Methods}

From the medical records examined it can be seen that: 8 patients were between 75 and 83 years old and weighed more than $40 \mathrm{~kg} ; 3$ patients were between 40 and 60 years old and weighed more than 40 $\mathrm{kg}$; 1 patient was 17 years old, with a body weight (BW) of $40 \mathrm{~kg}$.

Here are some data of the 12 patients observed: in two subjects it was necessary to increase the dose; in 10 subjects the single administration was decisive.

In the 12 patients under care, Mycamine ${ }^{\circledR}$ was used following hypovolemic postoperative shock; in some cases this added pathologies and/or complications (cardio-respiratory arrest, respiratory failure acute postoperative malignant neoplasm of the stomach). The adverse reactions most frequently observed in these patients were: anemia, hypokalemia, hypomagnesemia, phlebitis, nausea, vomiting, diarrhea, blood values indicating liver problems such as increased alkaline phosphatase, aspartate aminotransferase (AST) and alanine aminotransferase or bilirubin (ALT). Medical records studied in the period before our work showed that the use of micafungin and the side effects due to its use overlap with the data obtained during the reference period (from 01/06/2014 to $31 / 08 / 2014$ ).

In rats, ${ }^{7}$ a development of hepatocellular tumors was observed after a treatment period of 3 month. The data sheet recommends to monitor liver function closely during treatment and discontinue the drug in the presence of persistent elevations in ALT/AST; it can also cause kidney problems and kidney failure, for that reason, it is necessary to monitor renal function. In our study, 11 patients had a BW greater than $40 \mathrm{~kg}$ and 1 patient weighed $40 \mathrm{~kg}$; considered that the dose regimen of Mycamine ${ }^{\circledR}$ depends precisely on the patient's BW, the dose used was respectively 100 and $40 \mathrm{mg}$ (Table 1 ).

If the patient's response is inadequate, in the absence of modified culture exams or clinical improvement, the dose may be increased to $200 \mathrm{mg} /$ day in patients weighing $40 \mathrm{~kg}$ or to $4 \mathrm{mg} / \mathrm{kg} /$ day in patients weighing $\leq 40 \mathrm{~kg} .{ }^{8}$ Bearing in mind that the duration of treatment of invasive candidiasis must be at least 14 days, the antifungal treatment should be continued for at least a week after two negative blood cul- tures are obtained, and after the resolution of clinical signs and symptoms of infection. The duration of treatment in esophageal candidiasis should be at least one week after resolution of clinical signs and symptoms, while in the prophylaxis of Candida infection it should be at least a week after the restoration of the same values. Micafungin showed a low potential for induction of resistance phenomena, and various studies have highlighted effective action against the biofilm produced by Candida spp., found frequently in intravascular catheters and which often represent a source of candidemia. Mycamine ${ }^{\circledR}$ must be aseptically reconstituted and diluted at room temperature according to the following protocol: remove the plastic cap from the vial and the stopper disinfected with alcohol; slowly inject into each vial, along the inside wall and aseptic, $5 \mathrm{~mL}$ of sodium chloride solution for $9 \mathrm{mg} / \mathrm{mL}(0.9 \%)$ infusion or glucose solution for $50 \mathrm{mg} / \mathrm{mL}(5 \%)$ infusion (taken from a $100 \mathrm{~mL}$ bottle/bag), paying attention to minimize foaming. It is necessary to reconstitute a sufficient number of vials of Mycamine ${ }^{\circledR}$ to obtain the required dose in $\mathrm{mg}$; then gently rotate the vial, do not shake and allow the powder to dissolve completely; one must immediately use the concentrate (the vial is for single use). Once reconstituted, draw up all the concentrate from each vial and return into the vial/infusion bag from which it was originally collected, then gently invert the infusion bottle/bag to disperse the diluted solution, without shaking to avoid foaming. Do not use if the solution is cloudy and/or precipitated. Place the bottle/bag containing the diluted infusion solution in a sealed, opaque bag in order to protect it from light. The preparation of the solution for infusion is shown in Table 2.

After reconstitution and dilution, the solution should be administered by intravenous infusion within 1 hour, since infusions performed in the quickest time can cause frequent histamine-mediated reactions. If reconstitution and drug dilution takes place in controlled and validated aseptic conditions, the infusion bottle/bag dose can be reused, respecting the limit of time for which chemical and physical stability has been demonstrated. This way, in the case of administration in pediatric patients, where the bottle/bag is used only partially, subsequent administration can be made without wasting medication. ${ }^{5}$ This feature is an advantage for Mycamine ${ }^{\circledR}$ compared to other echinocandins both because the latter have a significantly lower time stability of the recon-

Table 1. Dose regimen of Mycamine ${ }^{\circledast}$ according to the indications in patients having different body weights.

\begin{tabular}{lll} 
Indication & $\mathrm{BW}>40 \mathrm{~kg}$ & $\mathrm{BW} \leq 40 \mathrm{~kg}$ \\
Treatment of invasive candidiasis & $100 \mathrm{mg} / \mathrm{day}$ & $2 \mathrm{mg} / \mathrm{kg} / \mathrm{day}$ \\
Treatment of esophageal candidiasis & $150 \mathrm{mg} / \mathrm{day}$ & $3 \mathrm{mg} / \mathrm{kg} / \mathrm{day}$ \\
\hline Prophylaxis of Candida infections & $50 \mathrm{mg} / \mathrm{day}$ & $1 \mathrm{mg} / \mathrm{kg} / \mathrm{day}$ \\
\hline
\end{tabular}

BW, body weight.

Table 2. Preparation of the solution for infusion.

\begin{tabular}{|c|c|c|c|c|}
\hline $\begin{array}{c}\text { Mycamine }{ }^{\circledR} 100 \mathrm{mg} \\
(\mathrm{n}=316)\end{array}$ & $\begin{array}{l}\text { Mycamine }{ }^{\circledR} \\
(\mathrm{mg} / \mathrm{mL}) \\
\text { or glucose }(5 \%)\end{array}$ & $\begin{array}{l}\text { Volume sodium } \\
\text { chloride }(0.9 \%)\end{array}$ & $\begin{array}{l}\text { Volume powder } \\
\text { reconstituted (mL) }\end{array}$ & $\begin{array}{l}\text { Infusion } \\
\text { standard }^{c} \\
(\mathrm{mg} / \mathrm{mL})\end{array}$ \\
\hline 50 & $1 \times 50$ & 5 & About $5(10 \mathrm{mg} / \mathrm{mL})$ & 0.5 \\
\hline 100 & $1 \times 100$ & 5 & About $5(20 \mathrm{mg} / \mathrm{mL})$ & 1.0 \\
\hline 150 & $1 \times 100+1 \times 50$ & 5 & About 10 & 1.5 \\
\hline 200 & $2 \times 100$ & 5 & About 10 & 2.0 \\
\hline
\end{tabular}

Values in brackets represent concentration. ${ }^{\circ}$ Final concentration. 
stituted product in the bag, and because Mycamine ${ }^{\circledR}$ is produced at dose strength and reduced price.

\section{Results and Discussion}

The clinical study, conducted at the Pharmacy of the Hospital in Marsala (belonging to the Provincial Health Authority No 9 of Trapani) shows that from 1/06/2014 to 31/08/2014, the vials of Mycamine ${ }^{\circledR}$ disbursed amounted to 50 . Twelve of these were administered to patients admitted to the intensive care unit of the Hospital P. Borsellino in Marsala. Micafungin has shown greater efficacy compared to fluconazole for the prophylaxis of invasive fungal infections, and was as effective as fluconazole in the treatment of esophageal candidiasis. The tolerable data and safety derive from different clinic trials. ${ }^{6}$ The relative results to safety hepatic profile demonstrate that micafungin can be considered imposable to amphotericin B liposomal, fluconazole and caspofungin. There have been rare reported non-functioning hepatic cases with final classification as possible or probable relative to micafungin treatment. Toxicological studies repeated at doses conducted in rats, have shown hepatotoxicity to micafungin treatment, with an increasing level of hepatic enzymes and the degeneration of hepatocytes. However, it is reasonable to underline that the irreversible hepatic structure alterations were highlighted for micafungin doses at plasmatic concentration of five to eight times higher than the highest dose reccomended for man.

\section{Conclusions}

In clinical studies, micafungin is as functional as amphotericin B liposomal and caspofungin in treatment for candid infection of the system. ${ }^{6}$ The same effectiveness is given in infections caused by Candida albicans and Candida non-albicans. ${ }^{5}$ At the end of the work and in light of the results obtained, we can say that compared to other echinocandins (anidulafungin and caspofungin), micafungin's favorable pharmacokinetic and pharmacodynamic profile is able to reach effective blood concentrations already in the first day, without the need of a loading dose, with favorable managerial and economic implications.

\section{References}

1. Sucher AJ. Echinocandins: the newest class of antifungal. Pharmacoterapy 2009;43:1647-57.

2. European Medicines Agency. Mycamine. Riassunto delle caratteristiche del prodotto (RCP). London: EMA; 2015. Available from: www.ema.europa.eu/docs/it_IT/document...WC500031075.pdf

3. Kawada M, Fukuoka N, Kondo M, et al. Pharmacokinetics of prophylactic micafungin in very-low-birth-weight infants. Pediatr Infect Dis J 2009;28:840-2.

4. Blyth CC, Palasanthiran P, O'Brien TA. Antifungal therapy in children with invasive fungal infections: a systematic review. Pediatrics 2007;119:772-84.

5. Baddley JW, Pappas PG. Antifungal combination therapy: clinical potential. Drugs 2005;65:1461-80.

6. Kuse ER, Chetchotisakd P, da Cunha CA, et al. Micafungin versus liposomal amphotericin B for candidaemia and invasive candidosis: a phase III randomised double-blind trial. Lancet 2007;369:1519-27.

7. European Medicines Agency. CHMP public assessment report for Mycamine. Procedure No. H/C/734. London: EMA; 2011. Available from: http:/www.ema.europa.eu/ema/index.jsp?curl=pages/medicines/human/medicines/000734/human_med_000911.jsp\&mid=W C0b01ac058001d124

8. Pappas PG, Rotstein CM, Betts RF, et al. Micafungin versus caspofungin for treatment of candidemia and other forms of invasive candidiasis. Clin Infect Dis 2007;45:883-93. 